\title{
Length of stay as quality indicator in emergency departments: analysis of determinants in the German Emergency Department Data Registry (AKTIN registry)
}

\author{
Ronny Otto $^{1}$ [ $\cdot$ Sabine Blaschke ${ }^{2} \cdot$ Wiebke Schirrmeister $^{1} \cdot$ Susanne Drynda $^{1} \cdot$ Felix Walcher $^{1} \cdot$ Felix Greiner $^{1}$
}

Received: 16 March 2021 / Accepted: 18 December 2021 / Published online: 6 January 2022

(c) The Author(s) 2022

\begin{abstract}
Several indicators reflect the quality of care within emergency departments (ED). The length of stay (LOS) of emergency patients represents one of the most important performance measures. Determinants of LOS have not yet been evaluated in large cohorts in Germany. This study analyzed the fixed and influenceable determinants of LOS by evaluating data from the German Emergency Department Data Registry (AKTIN registry). We performed a retrospective evaluation of all adult (age $\geq 18$ years) ED patients enrolled in the AKTIN registry for the year 2019. Primary outcome was LOS for the whole cohort; secondary outcomes included LOS stratified by (1) patient-related, (2) organizational-related and (3) structure-related factors. Overall, 304,606 patients from 12 EDs were included. Average LOS for all patients was $3 \mathrm{~h} 28 \mathrm{~min}(95 \% \mathrm{CI} 3 \mathrm{~h}$ $27 \mathrm{~min}-3 \mathrm{~h} 29 \mathrm{~min}$ ). Regardless of other variables, patients admitted to hospital stayed 64 min longer than non-admitted patients. LOS increased with patients' age, was shorter for walk-in patients compared to medical referral, and longer for non-trauma presenting complaints. Relevant differences were also found for acuity level, day of the week, and emergency care levels. We identified different factors influencing the duration of LOS in the ED. Total LOS was dependent on patientrelated factors (age), disease-related factors (presentation complaint and triage level), and organizational factors (weekday and admitted/non-admitted status). These findings are important for the development of management strategies to optimize patient flow through the ED and thus to prevent overcrowding.
\end{abstract}

Keywords Emergency department $\cdot$ Length of stay $\cdot$ Quality indicator $\cdot$ Registry

\section{Introduction}

Complexity of emergency treatment as well as the decision of priority have a substantial impact on emergency department (ED) processes [1,2]. The process within the ED usually starts with the admission of the emergency patient, followed by acuity assessment (triage), diagnosis, treatment initiation, and decisions on discharge or further inpatient treatment [3]. The periods between these procedures are defined as process times. They play an important role in the evaluation of the quality of care in EDs and are influenced

Ronny Otto

ronny.otto@med.ovgu.de

1 Department of Trauma Surgery, Otto Von Guericke University, Leipziger Str. 44, 39120 Magdeburg, Germany

2 Emergency Department, University Medicine Göttingen, Göttingen, Germany by various factors, including patient flow, the severity of the condition, and category of disease or injury. Evaluation of these process times by using routinely collected data permits transparent characterization of most ED processes, and thus, allows for the development of improvement strategies in ED performance [4-6]. One of the most important indicators of ED performance is the length of stay (LOS), which represents a highly relevant quality indicator (QI) [7, 8]. Therefore, it is suitable as a tool for evaluating the process quality and performance of an ED $[9,10]$.

Modelling of patient flow in EDs by established methods such as event simulation has previously been described in numerous studies, providing essential approaches for the optimization of ED performance [11-13]. Overcrowding is one of the most common problems observed in EDs and is mainly caused by an excessively long LOS within the $\mathrm{ED}$, leading to a disruption of all processes and a dramatic increase in risks of emergency treatment [14-16]. Therefore, it is important to evaluate all factors influencing the 
process times within the ED. These factors are classified into different categories: patient factors (demographic and health-related factors), organizational factors, and structural factors (emergency care levels).

In a systematic review by Hörster et al., 15 different process times, including repeatedly cited QIs, for EDs were described [17]. Using routine data taken from the Emergency Department Medical Record V2015.1 collected within the German Emergency Department Data Registry (AKTIN registry), six of the 15 process times could be calculated, namely, arrival up to initial clinical assessment, arrival to initial triage, arrival to initial treatment, time to computer tomography, LOS of admitted patients, and LOS of nonadmitted patients [18].

Previous studies on determinants were usually monocentric, based on small cohorts and only examined selected factors $[19,20]$. In order to identify factors that can be influenced, all possible determinants should be taken into account. In addition international studies are of limited value for analyzing the German health care system due to different, state specific organizational and structural characteristics of emergency care systems. In addition, no symptoms have been recorded in routine data sets so far. This study analyzed the LOS in the ED and its determinants by evaluating data sets in the AKTIN registry. Results were compared with international time targets that have previously been introduced in various countries to improve ED performance [21-24].

Methods

\section{Patients and study setting and data basis}

In 2019, 16 German hospitals, with an average total patient volume of about 40,000 emergencies per month, participated in the AKTIN registry. They are located throughout Germany, include university as well as non-university hospital EDs and cover all three levels of emergency care according to the specifications of the Federal Joint Committee [25], the highest decision-making body of the joint self-government of physicians, dentists, hospitals and health insurance funds in Germany. These levels are basic emergency care, extended emergency care and comprehensive emergency care. This subdivision was introduced in 2018 with regard to remuneration and is based on type and number of specialist departments, staffing with specialists, capacity to care for intensive care patients, medical-technical equipment and structures and processes of the ED. The base module of the German Emergency Department Medical Record V2015.1, published by the German Interdisciplinary Association of Critical Care and Emergency Medicine (DIVI e. V.), defines items such as the demographic data, Canadian Emergency Department Information System (CEDIS) Presenting Complaint List [26], acuity assessment (triage) according to the Manchester Triage System (MTS), and the Emergency Severity Index (ESI) as well as vital parameters, date/time, and diagnoses coded by the German modification of the International Classification of Diseases and Related Health Problems, 10th revision (ICD-10-GM) at the end of the ED treatment [27]. In this study, LOS was defined as the interval between $t 0$ and $t 1: t 0$ refers to the first timestamp recorded in the system (possible data items: time of administration, time of initial assessment, time of first physician contact), and $t 1$ is the timestamp of patient disposition (i.e., discharge in case of outpatient treatment or transfer in case of hospital admission). The data were documented for all patients as part of the routine documentation with the respective hospital information system.

The anonymized data were retrieved via the AKTIN registry (Project-ID 2020-001), enabling data protection-compliant access to the data stored in local data warehouses. Individual patient consent is not feasible in the context of an emergency situation. Instead, there is a strict data protection concept for the AKTIN registry and technical and organizational measures ensure anonymity [18]. Data request was reviewed by the scientific committee (review board) with regard to scientific merit, feasibility, ethics, and data protection issues [18, 28, 29]. The data protection work group of the Technologies, Methods, and Infrastructure for Networked Medical Research approved the privacy policy of the AKTIN registry. The AKTIN project was approved by the ethics committee of Otto von Guericke University, Medical Faculty, Magdeburg (160/50-23.11.2015).

\section{Inclusion and exclusion criteria and plausibility check}

All patients aged $\geq 18$ years attending an ED participating in the AKTIN registry during the study period in 2019 were included in this study. Only complete datasets were used for statistical analyses. Cases in which the discharge date was not documented, before $t 0$ or the calculated LOS seemed implausible were excluded. We used a threshold of $24 \mathrm{~h}$ as the upper limit for a very high, but still realistic LOS [30]. All patients who died in the ED were also excluded to avoid measurement errors of the LOS by evaluating the data item "time to death" as the time of discharge from the ED (i.e., pick-up time after death).

\section{Statistical analyses}

First, LOS was calculated for all patients. Additionally, LOS was stratified for different subgroups with respect to the parameters age, sex, referral, initial assessment, and disposition (Table 1). LOS in relation to the initial assessment was differentiated between the two triage systems MTS and ESI owing to different algorithms [31]. Additionally, LOS 
Table 1 Patients' characteristics and LOS in the ED

\begin{tabular}{|c|c|c|c|c|}
\hline \multirow[t]{2}{*}{$n=304,606$} & \multicolumn{4}{|l|}{ LOS (mins) } \\
\hline & $N(\%)$ & $\mathrm{M} \pm \mathrm{SD}$ & $95 \% \mathrm{CI}(\mathrm{M})$ & Median \\
\hline Total LOS & & $207.9 \pm 162.5$ & 207.3-208.5 & 171.3 \\
\hline Age (years), $M \pm S D$ & $54.9 \pm 22.0$ & & & \\
\hline $18-40$ & $96,999(31.8 \%)$ & $174.1 \pm 144.1$ & $173.2-175.0$ & 140.9 \\
\hline $41-60$ & $75,893(24.9 \%)$ & $203.8 \pm 159.5$ & $202.7-205.0$ & 167.2 \\
\hline $61-70$ & $39,057(12.8 \%)$ & $226.9 \pm 169.6$ & $225.2-228.5$ & 190.0 \\
\hline $71-80$ & $45,712(15.0 \%)$ & $237.1 \pm 172.5$ & $235.5-238.6$ & 200.0 \\
\hline$>81$ & $46,945(15.4 \%)$ & $240.1 \pm 172.8$ & $238.5-241.7$ & 204.4 \\
\hline \multicolumn{5}{|l|}{ Gender } \\
\hline Male & $155,316(51.0 \%)$ & $203.8 \pm 161.1$ & 203.0-204.6 & 167.0 \\
\hline Female & $149,123(48.9 \%)$ & $212.2 \pm 163.9$ & $211.3-213.0$ & 175.9 \\
\hline Diverse/no information & $167(0.05 \%)$ & $163.7 \pm 153.9$ & $140.1-187.2$ & 124.8 \\
\hline \multicolumn{5}{|l|}{ Referral } \\
\hline Walk-in patients & $125,166(46.0 \%)$ & $176.0 \pm 143.1$ & $175.2-176.8$ & 143.2 \\
\hline Emergency medical service & $87,114(32.0 \%)$ & $235.7 \pm 180.9$ & $234.5-236.9$ & 193.0 \\
\hline General practitioner (GP) & $43,086(15.8 \%)$ & $239.3 \pm 150.2$ & $237.9-240.7$ & 211.2 \\
\hline GP-based emergency care/practice & $11,224(4.1 \%)$ & $225.9 \pm 194.0$ & $222.4-229.5$ & 178.0 \\
\hline Referral from other clinics & $5654(2.1 \%)$ & $225.1 \pm 191.3$ & $220.1-230.0$ & 174.0 \\
\hline Total & $272,244(100 \%)$ & - & & - \\
\hline No information & $32,362(10.6 \%)$ & & & \\
\hline \multicolumn{5}{|l|}{ Acuity assessment (triage) } \\
\hline Red-immediate & $4372(1.6 \%)$ & a & & - \\
\hline Orange-very urgent & $33,310(12.0 \%)$ & - & & - \\
\hline Yellow—urgent & $106,073(38.3 \%)$ & - & & - \\
\hline Green-standard & $123,593(44.6 \%)$ & - & & - \\
\hline Blue-non-urgent & $9803(3.5 \%)$ & - & & - \\
\hline Total & $277,151(100 \%)$ & - & & - \\
\hline Without documented acuity assessment & $27,455(9.0 \%)$ & - & & - \\
\hline \multicolumn{5}{|l|}{ Disposition } \\
\hline Discharge (non-admitted) & $150,666(57.1 \%)$ & $183.5 \pm 140.6$ & $183.2-184.6$ & 152.0 \\
\hline Hospital-admission (admitted) & $98,592(37.4 \%)$ & $247.4 \pm 185.0$ & $246.2-248.5$ & 204.0 \\
\hline Discharge against medical advice (non-admitted) & $5292(2.0 \%)$ & $230.2 \pm 132.2$ & $226.6-233.7$ & 205.9 \\
\hline No medical contact (non-admitted) & $3392(1.3 \%)$ & $125.8 \pm 176.8$ & $119.8-131.7$ & 70.2 \\
\hline Treatment aborted by patient (non-admitted) & $2755(1.0 \%)$ & $196.3 \pm 163.1$ & $190.2-202.3$ & 158.5 \\
\hline Transfer to other clinics & $2021(0.8 \%)$ & $275.6 \pm 222.4$ & $265.9-285.3$ & 216.8 \\
\hline Other discharge (non-admitted) & $990(0.4 \%)$ & $153.0 \pm 180.8$ & $141.8-164.3$ & 100.4 \\
\hline Total & $263,708(100 \%)$ & & & \\
\hline Non-admitted & $163,095(62.3 \%)$ & $183.9 \pm 142.4$ & $183.2-184.6$ & 152.1 \\
\hline Admitted & $98,592(37.7 \%)$ & $247.4 \pm 185.0$ & $246.2-248.5$ & 204.0 \\
\hline Disposition not documented & $40,898(13.4 \%)$ & - & & - \\
\hline
\end{tabular}

M, mean; SD, standard deviation; LOS, length of stay; 95\% CI, 95\% confidence interval of mean; ED, emergency department; MTS, Manchester Triage System; ESI, Emergency Severity Index

${ }^{\text {a }}$ The LOS for acuity assessment was considered separately for MTS and ESI in Table 4 was compared with respect to specific "time targets" [21-24] (Table 2). For further analysis, patients were assigned to traumatological and non-traumatological care according to their complaint listed in CEDIS [32] (Table 3). Finally, LOS was analyzed in relation to the days of the week and the seasonal pattern.
All calculations and graphics were created using the $\mathrm{R}$ statistical software [33]. The individual process times were presented descriptively as mean \pm standard deviation (if not noted otherwise), additionally the $95 \%$ confidence interval of the mean is reported. In Table 1 , the median was also shown due to a lack of normal distribution of 
Table 2 Time targets

\begin{tabular}{|c|c|c|c|c|c|}
\hline \multirow[t]{3}{*}{ Time targets } & \multirow[t]{3}{*}{ Country } & \multicolumn{4}{|c|}{ AKTIN registry data } \\
\hline & & \multirow[t]{2}{*}{$N(\%)$} & LOS (mins) & LOS ADM & LOS non-ADM \\
\hline & & & $\mathrm{M} \pm \mathrm{SD}(95 \% \mathrm{CI})$ & $\begin{array}{l}\mathrm{M} \pm \mathrm{SD} \\
95 \% \mathrm{CI}(\% \text { of } N)\end{array}$ & $\begin{array}{l}\mathrm{M} \pm \mathrm{SD} \\
95 \% \mathrm{CI}(\% \text { of } N)\end{array}$ \\
\hline $4 \mathrm{~h}$ & $\begin{array}{l}\text { Australia (80\%), England } \\
\text { (98\%), Canada (90\% } \\
\text { non-admitted) }\end{array}$ & $211,997(69.6 \%)$ & $129.6 \pm 59.9(129.4-129.9)$ & $\begin{array}{l}145.3 \pm 55.7(144.8-145.7) \\
(28.3 \%)\end{array}$ & $\begin{array}{l}123.3 \pm 60.0(123.0-123.7) \\
(58.0 \%)\end{array}$ \\
\hline $6 \mathrm{~h}$ & New Zealand (95\%) & $268,582(88.2 \%)$ & $163.8 \pm 86.3(163.5-164.2)$ & $\begin{array}{l}184.9 \pm 82.6(184.4-185.5) \\
(30.6 \%)\end{array}$ & $\begin{array}{l}152.8 \pm 85.1(152.4-153.2) \\
(55.5 \%)\end{array}$ \\
\hline $8 \mathrm{~h}$ & Canada ( $90 \%$ admitted) & $289,318(95.0 \%)$ & $\begin{array}{l}181.5 \pm 105.0(181.1- \\
181.8)\end{array}$ & $\begin{array}{l}207.1 \pm 103.8(206.1- \\
207.8)(31.5 \%)\end{array}$ & $\begin{array}{l}166.6 \pm 101.3(166.1- \\
167.1)(54.5 \%)\end{array}$ \\
\hline
\end{tabular}

ADM, admitted; non-ADM, non-admitted; M, mean; SD, standard deviation; 95\% CI, 95\% confidence interval of mean; LOS, length of stay; AKTIN, the German Emergency Department Data Registry

Table 3 LOS (mins) in relation to presenting complaints, summarised for trauma and non-trauma, and the top 10

\begin{tabular}{|c|c|c|c|c|}
\hline $\begin{array}{l}\text { CEDIS code } \\
N=232,624(70,798(23.2 \%) \\
\text { missing data) }\end{array}$ & $\begin{array}{l}\operatorname{LOS}(\min ) \\
\mathrm{M} \pm \mathrm{SD}(95 \% \mathrm{CI})\end{array}$ & $\begin{array}{l}\text { ADM } \\
\text { M }(\%)^{\mathrm{a}} \\
(95 \% \mathrm{CI})^{\mathrm{a}}\end{array}$ & $\begin{array}{l}\text { Non-ADM } \\
\text { M }(\%)^{\mathrm{a}} \\
(95 \% \mathrm{CI})^{\mathrm{a}}\end{array}$ & $\begin{array}{l}\text { ADM vs. non-ADM } \\
p(r)\end{array}$ \\
\hline Trauma $(n=50,208,21.6 \%)$ & $149.8 \pm 121.8(148.8-150.9)$ & 219.9 (19.8) (216.2-223.6) & $135.9(80.2)(134.9-137.0)$ & $<0.001(0.270 * *)$ \\
\hline Non-trauma $(n=182,416,78.4 \%)$ & $223.5 \pm 173.2(222.7-224.3)$ & $257.8(44.6)(256.5-259.2)$ & $199.7(55.4)(198.7-200.7)$ & $<0.001(0.192 * *)$ \\
\hline 251 -abdominal pain $(n=19,795)$ & $250.4 \pm 175.9(247.9-252.8)$ & $272.1(45.3)(268.2-276.0)$ & $232.8(45.4)(229.8-236.1)$ & $<0.001\left(0.119^{* *}\right)$ \\
\hline $\begin{array}{l}\text { 556-upper extremity injury } \\
(n=13,077)\end{array}$ & $143.3 \pm 105.6(141.5-145.1)$ & 215.1 (11.9) (207.4-222.9) & 134.9 (75.5) (133.1-136.7) & $<0.001\left(0.245^{* *}\right)$ \\
\hline $\begin{array}{l}557 \text {-lower extremity injury } \\
(n=12,544)\end{array}$ & $150.0 \pm 105.8(148.2-151.9)$ & $211.2(19.1)(205.8-216.6)$ & $135.7(64.0)(133.8-137.6)$ & $<0.001\left(0.315^{* * *}\right)$ \\
\hline $\begin{array}{l}\text { 555-lower extremity pain } \\
(n=11,542)\end{array}$ & $166.0 \pm 109.5(164.0-168.0)$ & 214.5 (20.0) (209.4-219.6) & $154.0(73.3)(151.9-156.2)$ & $<0.001(0.243 * *)$ \\
\hline $\begin{array}{l}\text { 554-upper extremity pain } \\
(n=10,586)\end{array}$ & $158.8 \pm 110.1(156.7-160.9)$ & $216.4(14.0)(209.1-223.6)$ & 150.7 (79.4) (148.6-152.9) & $<0.001(0.207 * *)$ \\
\hline $\begin{array}{l}651 \text { —shortness of breath } \\
(n=9,796)\end{array}$ & $246.9 \pm 178.8(243.4-250.4)$ & $256.6(62.6)(251.9-261.2)$ & $243.9(23.1)(237.4-250.5)$ & $0.326\left(0.010^{*}\right)$ \\
\hline $\begin{array}{l}\text { 003 - chest pain/cardiac features } \\
(n=9,692)\end{array}$ & $271.4 \pm 204.4(267.3-275.4)$ & $296.3(43.4)(289.3-303.3)$ & $277.7(38.2)(272.1-283.2)$ & $0.158\left(0.015^{*}\right)$ \\
\hline 551 -back pain $(n=9,138)$ & $197.2 \pm 134.3(194.4-199.9)$ & $231.7(29.2)(225.8-237.6)$ & 183.7 (65.6) (180.7-186.7) & $<0.001\left(0.158^{* *}\right)$ \\
\hline $\begin{array}{l}409 \text { - extremity weakness/symp- } \\
\text { toms of CVA }(n=8,290)\end{array}$ & $237.1 \pm 177.8(233.3-240.9)$ & $226.3(73.9)(222.0-230.6)$ & $265.6(17.1)(256.0-275.2)$ & $<0.001\left(0.116^{* *}\right)$ \\
\hline $\begin{array}{l}\text { 704-laceration/puncture } \\
(n=7,468)\end{array}$ & $128.9 \pm 107.4(126.4-131.3)$ & $206.0(11.1)(194.9-217.0)$ & $121.6(81.4)(119.2-123.9)$ & $<0.001\left(0.246^{* *}\right)$ \\
\hline
\end{tabular}

CEDIS, Canadian Emergency Department Information System; ADM, admitted; Non-ADM, non-admitted; M, mean; SD, standard deviation; 95\% CI, 95\% confidence interval of mean; LOS, length of stay; CVA, cerebrovascular accident

$*$ No effect, **small effect, ***moderate effect

${ }^{\mathrm{a}}$ Related to all cases with documentation of a presenting complaint

the data. Comparisons between LOS for binary variables were performed with the Mann-Whitney $U$ test. For variables with more categories, the Kruskal-Wallis test was used. Dunn's test was used as a post hoc test for the Kruskal-Wallis test. Differences were considered statistically significant at $p<0.05$. The $p$ value was adjusted using the Benjamini-Hochberg procedure. Due to the high number of cases, even small differences can be significant.
For this reason, the effect sizes $\eta^{2}$ (Kruskal-Wallis) and $r$ (Mann-Whitney $U$ ) were also indicated. These were interpreted with: $\eta^{2} 0.01$ to $<0.06$ (small effect), 0.06 to $<0.14$ (moderate effect) and $\geq 0.14$ (large effect) [34]. The following values were applied to $r$ : 0.10 to $<0.3$ (small effect), 0.30 to $<0.5$ (moderate effect) and $\geq 0.5$ (large effect) [35]. 


\section{Results}

Twelve AKTIN EDs participated in the study, which included four extended emergency care providers (EECP), seven comprehensive emergency care providers (CECP), and one basic emergency care provider (BECP). The resulting dataset included 321,498 cases. Participating hospitals provided data sets from about 12,000 to 38,000 adult patients per clinic during the study period. Seven hospitals used MTS, and five hospitals used ESI as the triage system.

A total of $100 \%$ of the admission dates were available. The following data sets were excluded: 15,477 (4.3\%) data sets due to missing discharge dates; 1189 records $(0.38 \%)$ with a calculated LOS of $>24 \mathrm{~h}$; and $226(0.07 \%)$ patients who died in the ED. After data set cleaning, 304,606 valid data sets were included in the analysis as outlined in Fig. 1.

\section{LOS}

The mean LOS in the ED was $3 \mathrm{~h} 28$ min $(95 \%$ CI $3 \mathrm{~h}$ $27 \mathrm{~min}-3 \mathrm{~h} 29 \mathrm{~min}$ ) with a minimum of $<1 \mathrm{~min}$ and a maximum of $24 \mathrm{~h}$ (Table 1). The minimum LOS resulted from patients leaving the ED without contact with a physician or being transferred to another ward immediately after arrival (e.g., delivery room). Patients admitted or transferred to another hospital mainly accounted for the maximum LOS.

Of all patients, $69.6 \%$ left the ED within four hours. Admitted patients had a 20 min higher LOS than nonadmitted patients. Within $6 \mathrm{~h}, 88.2 \%$ of the patients were discharged, with an average LOS of $2 \mathrm{~h} 43 \mathrm{~min}(95 \% \mathrm{CI} 2 \mathrm{~h}$ $43 \mathrm{~min}-2 \mathrm{~h} 44 \mathrm{~min}$ ). $5 \%$ of all emergency patients left the ED after $8 \mathrm{~h}$, their mean LOS was $11 \mathrm{~h} 48 \mathrm{~min}(95 \% \mathrm{CI} 11 \mathrm{~h}$ $44 \mathrm{~min}-11 \mathrm{~h} 51 \mathrm{~min}$ ), with $53.1 \%$ of admitted patients in this group (Table 2).

\section{LOS depending on patient-related factors}

The analysis of demographic data (Table 1) revealed no gender differences in LOS in male and female ED patients $(51.0 \%$ vs. $48.9 \%)$ with an average LOS of over $3 \mathrm{~h}$. LOS increased significantly with respect to the age of ED patients. The mean age was $55 \pm 22$ years, with women being on average 2 years older than men ( 56 vs. 54 years). Patients aged between 18 and 40 years stayed in the ED for an average of 2 h 55 min (95\% CI 2 h 53 min-2 h 55 min), whereas
Fig. 1 Evaluation of AKTIN registry data according to inclusion and exclusion criteria. ED, emergency department; pat., patients

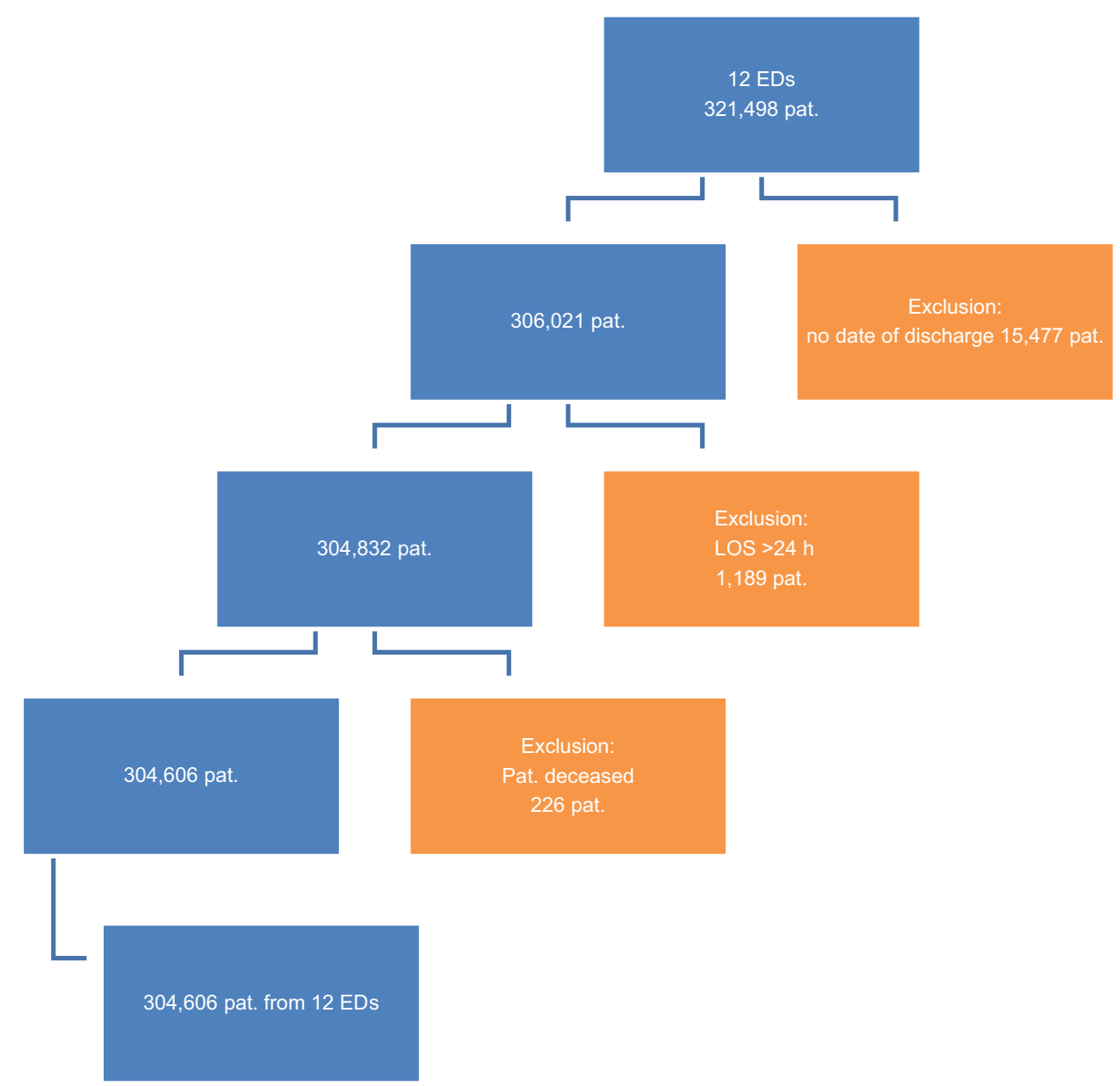


patients aged $\geq 80$ years were in the ED for up to $4 \mathrm{~h}$. However, in contrast to the age group of 18-40 years with only $15.4 \%$ of admitted patients, $52 \%$ of those over 80 years were admitted to the hospital.

Most ED patients were walk-in patients (46.0\%) who stayed for the shortest time ( 2 h $56 \mathrm{~min}, 95 \%$ CI $2 \mathrm{~h}$ $55 \mathrm{~min}-2 \mathrm{~h} 57 \mathrm{~min}$ ). Only $19.4 \%$ of the patients were admitted. For the other types of referrals (25.8\% via emergency medical service and $15.8 \%$ via the general practitioner), LOS was over $3 \mathrm{~h} 45 \mathrm{~min}$ (Table 1).

\section{LOS as a function of disease-related factors}

The ten most frequent presenting complaints according to the CEDIS codes comprised $36.7 \%$ of all cases attending EDs. As outlined in Table 3, patients presenting with abdominal pain, cardiac chest pain, and shortness of breath exhibited the highest LOS. Patients with injuries and pain in the upper and lower extremities were released from the ED on average up to $1 \mathrm{~h} 40$ min earlier than patients with abdominal pain, chest pain, and shortness of breath. Patients with laceration/puncture exhibited the shortest LOS. In all categories except for shortness of breath and cardiac chest pain, LOS was significantly longer for admitted patients than for non-admitted patients.

Overall, the LOS of non-trauma patients in the ED was $1 \mathrm{~h} 14$ min longer than that of trauma patients (Table 3). Approximately $44.6 \%$ of non-trauma patients and $19.8 \%$ of the trauma patients were admitted to the hospital. In the case of hospital admission, non-trauma patients stayed for approximately $40 \mathrm{~min}$ longer in the ED than trauma patients (3 h 39 min vs. 4 h $17 \mathrm{~min}, p<0.001, r=0.082$ ). Similarly, in the case of discharge, non-trauma patients had $60 \mathrm{~min}$ longer LOS than trauma patients ( $2 \mathrm{~h} 15 \mathrm{~min}$ vs. $3 \mathrm{~h} 19 \mathrm{~min}$, $p<0.001, r=0.228$ ).

\section{LOS in relation to the acuity assessment (triage system)}

In hospitals using MTS as triage system ( $n=7$; LOS: $3 \mathrm{~h}$ $21 \mathrm{~min}$ (95\% CI 3 h $20 \mathrm{~min}-3$ h $22 \mathrm{~min})$ ), most patients were categorized as level 3-yellow (34.2\%) and level 4-green (51.1\%). Level 3 had an LOS of 3 h 45 min $(95 \%$ CI $3 \mathrm{~h}$ $43 \mathrm{~min}-3 \mathrm{~h} 26 \mathrm{~min}$ ), but fewer patients were admitted for treatment than patients in level 1-red or 2-orange. In case of admission, patients in level 1 had the shortest LOS of $2 \mathrm{~h}$ 3 min (95\% CI 1 h 57 min-2 h 10 min), whereas patients in levels 3-5 stayed for an average of $4 \mathrm{~h}$ in the ED. Strong differences in LOS between triage levels (except for level 3 vs. level 5) were detected $(p<0.001)$. In non-admitted cases, patients in level 5 had the shortest LOS ( 2 h 24 min, 95\% CI $2 \mathrm{~h} 21 \mathrm{~min}-2 \mathrm{~h} 28 \mathrm{~min}$ ) and patients in level 2 had the longest LOS (4 h $10 \mathrm{~min}, 95 \%$ CI 4 h 5 min-4 h $16 \mathrm{~min}$ ) in the
ED. The LOS decreased from level 2-5 patients by approximately $2 \mathrm{~h}$. Similarly, significant differences in the LOS between triage levels (except for level 1 vs. level 3) were also found in the non-admitted group $(p<0.001)$ (Table 4 , Fig. 2).

In EDs using the ESI triage system $(n=5 ; \mathrm{LOS}, 3 \mathrm{~h}$ 38 min (95\% CI 3 h 17 min-3 h 19 min)), most patients were classified as level $3(46.2 \%)$ and level 4 (31.9\%). Patients in level 5 had the lowest LOS of 2 h 24 min $(95 \%$ CI $2 \mathrm{~h}$ $18 \mathrm{~min}-2 \mathrm{~h} 31 \mathrm{~min}$ ), and patients in level 3 had the longest LOS of 4 h 11 min (95\% CI 4 h 9 min-4 h 13 min). Overall, the LOS, except for level 1 , was $>4 \mathrm{~h}$. No differences in LOS were detected between levels 2, 4, and 5. Notably, the proportion of admitted patients dropped sharply by $75 \%$ from level 1 to level 5. From levels 2-5, the proportion of non-admitted patients increased and, correspondingly, the LOS decreased up to $1 \mathrm{~h} 53 \mathrm{~min}$. No significant differences in LOS were detected for non-admitted patients between triage level 1 vs. level $4 / 5$ as well as for both admitted and non-admitted patients between triage levels 1 and 2 (Table 4, Fig. 2),

\section{LOS in relation to weekdays and time of year}

In the AKTIN ED cohort, the shortest LOS was observed on weekends ( 3 h 13 min, 95\% CI 3 h 12 min-3 h 14 min) and longest LOS on Mondays ( $3 \mathrm{~h} 40 \mathrm{~min}, 95 \%$ CI $3 \mathrm{~h}$ $39 \mathrm{~min}-3 \mathrm{~h} 42 \mathrm{~min}$ ). Regardless of the day of the week, longer LOS was observed for admitted patients than for non-admitted patients with a range of 58-70 min. Relevant seasonal fluctuations were not observed.

\section{LOS depending on emergency care levels}

For comparison of LOS in terms of the emergency care levels, one ED classified as a basic emergency care provider was excluded from the calculation to preserve the data protection concept of the AKTIN registry. EDs that are classified as extended emergency care providers have 31 min shorter LOS than clinics that are classified as comprehensive emergency care providers ( $3 \mathrm{~h} 10 \mathrm{~min}$ vs. $3 \mathrm{~h}$ $41 \mathrm{~min}, p<0.001)$. Additionally, the LOS was higher for admitted (EECP 3 h 48 min vs. CECP 4 h 26 min, $p<0.001$ ) patients than for non-admitted patients (EECP $2 \mathrm{~h} 45 \mathrm{~min}$ vs. CECP 3 h 19 min, $p<0.001$ ). However, both EECP and CECP showed a difference in LOS between admitted vs. non-admitted patients at 30 and $40 \mathrm{~min}$, respectively. For trauma patients, no difference between the emergency care levels was found. However, non-trauma patients treated by CECP had 36 min longer LOS than those treated by EECP $(p<0.001)$. With EECP, patients with abdominal pain and shortness of breath had an LOS of $3 \mathrm{~h} 38 \mathrm{~min}$ and $3 \mathrm{~h} 37 \mathrm{~min}$, respectively. With CECP, the LOS was $47 \mathrm{~min}$ 
Table 4 LOS in EDs using MTS $(n=7)$ or ESI $(n=5)$

\begin{tabular}{|c|c|c|c|c|c|c|c|}
\hline \multirow[t]{2}{*}{$\operatorname{MTS}(n=7)$} & \multirow[t]{2}{*}{$N(\%)$} & \multirow{2}{*}{$\begin{array}{l}\text { LOS (mins) } \\
\mathrm{M} \pm \mathrm{SD}(95 \% \mathrm{CI})\end{array}$} & \multirow{2}{*}{$\begin{array}{l}\mathrm{ADM} \\
\%\end{array}$} & \multirow{2}{*}{$\begin{array}{l}\mathrm{ADM} \\
p<0.001, \eta^{2}=0.035 * \\
\mathrm{M} \pm \mathrm{SD}(95 \% \mathrm{CI})\end{array}$} & \multirow{2}{*}{$\begin{array}{l}\text { Non-ADM } \\
\%\end{array}$} & \multirow{2}{*}{$\begin{array}{l}\text { Non-ADM } \\
p<0.001, \eta^{2}=0.038^{*} \\
\mathrm{M} \pm \mathrm{SD}(95 \% \mathrm{CI})\end{array}$} & \multirow{2}{*}{$\begin{array}{l}\text { ADM vs. Non-ADM } \\
p(r)\end{array}$} \\
\hline & & & & & & & \\
\hline Red & $2918(1.59 \%)$ & $\begin{array}{l}136.4 \pm 130.3 \\
\quad(131.6-141.1)\end{array}$ & 46.8 & $\begin{array}{l}123.4 \pm 116.3(117.2 \\
-129.6)\end{array}$ & 6.9 & $\begin{array}{l}218.6 \pm 192.3 \\
(192.0-245.3)\end{array}$ & $<0.001(0.231 * *)$ \\
\hline Orange & $16,046(8.7 \%)$ & $\begin{array}{l}218.8 \pm 162.7 \\
\quad(216.3-221.3)\end{array}$ & 53.2 & $\begin{array}{l}197.8 \pm 158.3 \\
(194.4-201.2)\end{array}$ & 22.6 & $\begin{array}{l}250.7 \pm 172.8 \\
\quad(245.1-256.3)\end{array}$ & $<0.001(0.199 * *)$ \\
\hline Yellow & $62,837(34.2 \%)$ & $\begin{array}{l}225.2 \pm 158.4 \\
\quad(223.9-226.4)\end{array}$ & 37.6 & $\begin{array}{l}234.6 \pm 167.3 \\
\quad(232.5-236.8)\end{array}$ & 43.8 & $\begin{array}{l}206.6 \pm 152.2 \\
\quad(204.8-208.4)\end{array}$ & $<0.001\left(0.105^{* *}\right)$ \\
\hline Green & $93,786(51.1 \%)$ & $\begin{array}{c}187.9 \pm 144.8 \\
(187.0-188.9)\end{array}$ & 23.7 & $\begin{array}{l}248.9 \pm 170.5 \\
(246.7-251.2)\end{array}$ & 67.9 & $\begin{array}{c}166.8 \pm 128.2 \\
(165.8-167.8)\end{array}$ & $<0.001(0.279 * *)$ \\
\hline Blue & $7994(4.4 \%)$ & $\begin{array}{l}161.1 \pm 151.9 \\
(157.8-164.4)\end{array}$ & 15.9 & $\begin{array}{l}237.9 \pm 183.9 \\
(227.8-248.0)\end{array}$ & 74.6 & $\begin{array}{l}144.6 \pm 135.9 \\
(141.1-148.0)\end{array}$ & $<0.001(0.259 * *)$ \\
\hline \multirow[t]{2}{*}{$\operatorname{ESI}(n=5)$} & $N(\%)$ & LOS (min) & $\mathrm{ADM}$ & $\begin{array}{l}\mathrm{ADM} \\
p<0.001 \\
\eta^{2}=0.035^{* *}\end{array}$ & Non-ADM & $\begin{array}{l}\text { Non-ADM } \\
p<0.001 \\
\eta^{2}=0.104 * * *\end{array}$ & ADM vs. non-ADM \\
\hline & & $\mathrm{M} \pm \mathrm{SD}(95 \% \mathrm{CI})$ & $\%$ & $\mathrm{M} \pm \mathrm{SD}(95 \% \mathrm{CI})$ & $\%$ & $\mathrm{M} \pm \mathrm{SD}(95 \% \mathrm{CI})$ & $p(r)$ \\
\hline Red & $1454(1.55 \%)$ & $\begin{array}{c}168.8 \pm 182.3 \\
(159.4-178.2)\end{array}$ & 85.4 & \multicolumn{2}{|c|}{$\begin{array}{l}169.1 \pm 183.6(158.9-10.1 \\
179.4)\end{array}$} & $\begin{array}{l}162.1 \pm 175.6(133.5- \\
190.8)\end{array}$ & $0.423(0.02 *)$ \\
\hline Orange & $17,264(18.5 \%)$ & $\begin{array}{l}247.0 \pm 177.8 \\
\quad(244.3-249.6)\end{array}$ & 63.0 & \multicolumn{2}{|c|}{$\begin{array}{l}250.7 \pm 181.8(247.3-28.1 \\
254.1)\end{array}$} & $\begin{array}{l}242.9 \pm 160.7(238.4- \\
247.5)\end{array}$ & $0.854\left(0.001^{*}\right)$ \\
\hline Yellow & $43,236(46.2 \%)$ & $\begin{array}{l}251.3 \pm 179.6 \\
(249.6-253.0)\end{array}$ & 45.4 & \multicolumn{2}{|c|}{$\begin{array}{l}287.6 \pm 208.9(284.6-50.5 \\
290.5)\end{array}$} & $\begin{array}{l}219.8 \pm 139.6(217.9- \\
221.7)\end{array}$ & $<0.001\left(0.190^{* *}\right)$ \\
\hline Green & $29,807(31.9 \%)$ & $\begin{array}{l}162.2 \pm 120.9 \\
(160.8-163.6)\end{array}$ & 10.4 & \multicolumn{2}{|c|}{$\begin{array}{l}247.4 \pm 174.4(241.3-87.1 \\
253.6)\end{array}$} & $\begin{array}{l}152.1 \pm 107.8(150.8- \\
153.4)\end{array}$ & $<0.001\left(0.215^{* *}\right)$ \\
\hline Blue & $1809(1.9 \%)$ & $\begin{array}{l}144.5 \pm 140.1 \\
\quad(138.0-150.9)\end{array}$ & 9.7 & \multicolumn{2}{|c|}{$\begin{array}{l}246.3 \pm 201.2(216.3-87.3 \\
276.2)\end{array}$} & $\begin{array}{l}130.5 \pm 119.0(124.7- \\
136.4)\end{array}$ & $<0.001\left(0.193^{* *}\right)$ \\
\hline
\end{tabular}

ADM, admitted; Non-ADM, non-admitted; M, mean; SD, standard deviation; 95\% CI, 95\% confidence interval of mean; LOS, length of stay; ED, emergency department; MTS, Manchester Triage System; ESI, Emergency Severity Index

$*$ No effect, $* *$ small effect, $* * *$ moderate effect

Fig. 2 LOS (mins) for levels 1-5, MTS, and ESI for all cases. LOS, length of stay; MTS, Manchester Triage System; ESI, Emergency Severity Index
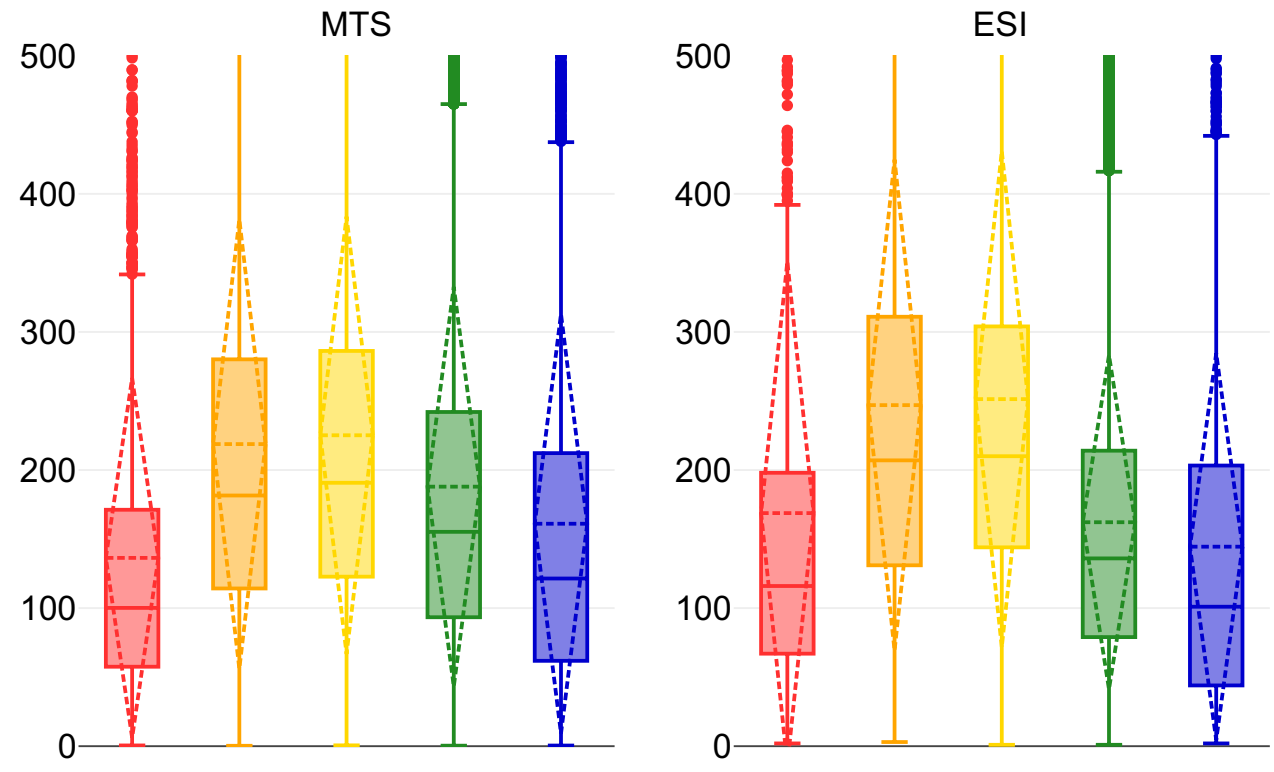

1-immediate

2-very urgent

5-non-urgent 3-urgent

4-standard 
(abdominal pain) and 64 min (shortness of breath) higher than with EECP.

\section{Discussion}

Our results revealed important findings for the development of strategies to improve ED performance. The mean LOS of $3 \mathrm{~h} 28 \mathrm{~min}$ for all patients included in the study is higher than that reported in other studies. Rygiel et al. [19] reported an LOS of $<3 \mathrm{~h}$, and Biber et al. [20] described a median LOS of $1 \mathrm{~h} 47 \mathrm{~min}$ with a maximum LOS of $>3 \mathrm{~h}$. In contrast to our analysis, both studies were single-centre analyses, including only 29,391 and 4653 patients, respectively.

With respect to patient-related factors, gender differences between the LOS in EDs were not detected in our study. In line with the findings of other studies [20,36], our results show that the LOS and the percentage of admitted patients increase with age. Self-admitted patients had a shorter LOS of up to $60 \mathrm{~min}$ than patients with other modes of referral. However, the rate of admittance for inpatient treatment of self-admitted ED patients was 35\% below that for patients referred to the ED by a general practitioner.

Regarding the leading symptoms and disease-associated factors, patients with cardiac chest pain, shortness of breath, or abdominal pain had the highest LOS in the ED. For all three main symptoms, a differential diagnosis must rule out a serious, potentially life-threatening condition, such as acute myocardial infarction or acute abdominal pain. Sometimes waiting for lab results or monitoring the patient in the initial phase is needed. This may also explain the non-existent differences between inpatient and outpatient treatment in some of these groups. Non-admitted trauma patients were discharged from the ED relatively quickly at $2 \mathrm{~h} 15 \mathrm{~min}$ compared with their admitted counterparts at $3 \mathrm{~h} 40 \mathrm{~min}$ $(p<0.001)$. In our study, the shortest LOS was found for the leading symptom "laceration/puncture".

For acuity assessment, our study showed a comparable association of the LOS with the triage level, which was already described in previous publications [19, 37]. Thus, the LOS was up to $2 \mathrm{~h}$ shorter for patients who required immediate or very urgent care (levels 1 and 2) and those who were admitted to the hospital after ED treatment than for patients in levels 3-5.

In our study, hospital admission of emergency patients was found to be one of the major relevant factors associated with a higher LOS. The longer LOS of admitted patients compared with non-admitted patients are attributable to the amount of time spent in the ED for necessary diagnostics. The waiting time for patients to be transferred to the specialist department plays a major role because the bed capacities in specialist departments are usually not available ad hoc due to the so-called access block [14]. Only in two scenarios, hospital admission was not associated with a higher LOS. In EDs using MTS as a triage system, admitted patients classified in the categories of red and orange had 33-min and 56-min shorter LOSs, respectively. In the second scenario, admitted patients with extremity weakness/symptoms of cerebrovascular accident as presenting complaint also had up to 39 min shorter LOS than non-admitted patients with the same presentation complaint. These are patients with suspected stroke needing immediate transfer to a special monitoring unit (stroke unit) according to international standardised ED protocols.

For organizational factors, our study results revealed significantly shorter LOS on weekends than on working days. The LOS was surprisingly up to $40 \mathrm{~min}$ shorter, but the number of patients was only $2 \%$ lower on average. Considering that the number of staff is usually reduced on weekends, this finding is remarkable. A possible explanation for this observation could be the increased use of the EDs by patients with minor complaints and less diagnostic effort outside the opening hours of general practitioners, but also the absence of referrals of more severe cases by general practitioners on weekends. Another explanation could be that on weekends, patient care is sometimes more focused as emergencies do not have to be scheduled between elective cases.

Several countries introduced "time targets" to evaluate emergency medical services, enabling a comparison of our findings with those in the international context. The 4-h target implemented in Australia (80\%), Great Britain (98\%), and Canada (90\%) was not achieved in our cohort of AKTIN EDs during the observation period: $69.6 \%$ of patients were discharged from the ED within $4 \mathrm{~h}, 88.2 \%$ after $6 \mathrm{~h}$, and $5 \%$ of all emergency patients left the ED after $8 \mathrm{~h}$. In comparison to international findings, our findings could be explained by differences in general and structural settings within the EDs. Particularly, EDs in Anglo-Saxon countries have been independent specialist departments for many years, and clinical emergency medicine represents a clearly defined medical specialty. In contrast, the minimum structural and procedural requirements as well as the establishment of a central ED were not legally binding in Germany until 2018 [25]. Baier et al. describe the different structures of emergency departments from different countries [38].

The reasons for the longer LOS in EDs with a higher care level may be due to different patient characteristics and/or the availability of more diagnostic and therapeutic options. However, a longer LOS in the ED does not inevitably result in a poorer quality of care: the discharge or transfer of an emergency patient should only be initiated after the completion of comprehensive diagnostics to ensure patient safety and to reduce the risk of adverse events even if it involves a longer LOS. Therefore, we suggest classifying the LOS as a performance measure rather than a quality indicator [39]. The influence of LOS on the medium-term patient outcome 
and thus its value as a quality indicator is currently being examined in the ENQuIRE project by linking AKTIN registry data with claims data from one public health insurance [40].

\section{Limitations}

Our data is process-generated data. Hence, the validity of documented timestamps must be considered when evaluating LOS. While the time of admission is usually recorded very accurately (entering insurance information into the system and performing the triage), the validity of other timestamps remains a challenge in most EDs: When or how is the "medical contact" operationalized or the "discharge" scheduled? For example, a bias can arise if patients leaving the ED are not "discharged" immediately from the documentation system but only later, for example, by administrative staff closing the patient file. This can particularly occur during resuscitation, where emergency treatment is in focus, and documentation is performed with a time delay.

\section{Conclusions}

Our study shows that the total LOS in the ED mainly depends on patient-related factors (age), disease-related factors (presenting complaint and triage level), and organizational factors (weekday and disposition). Analyzing large datasets of the AKTIN registry allows for a valid evaluation of the LOS in EDs at all emergency care levels. Even if many of the influencing factors, e.g. age, gender and presenting complaints, cannot be changed as such, their identification is important. Real-time tracking of data in the ED as well as an optimized management of processes may help to avoid delays in diagnostics and interventions and improve the flow of patients through the ED. In addition, a baseline for external comparisons is needed. Our results support the development of strategies to optimize the processes in the ED. This applies, for example, to the reduction of the "boarding time" between treatment completion and discharge time. Future studies should therefore not only look at the LOS as a whole, but also take a closer look at such sub-processes during emergency treatment.

\footnotetext{
Author contributions All authors provided meaningful contributions to the work for justifying the authorship and have approved the final manuscript submitted for publication. RO drafted the article and takes responsibility for the manuscript. Interpretation of the data: $\mathrm{RO}, \mathrm{SB}$, and FG. Critical revision of the manuscript for important intellectual content: SB, FG, WS, SD, and FW. Concept and design: FG and WS. Statistical analyses: RO.
}

Funding Open Access funding enabled and organized by Projekt DEAL. None.

\section{Declarations}

Conflict of interest The authors declare that they have no conflicts of interest.

Open Access This article is licensed under a Creative Commons Attribution 4.0 International License, which permits use, sharing, adaptation, distribution and reproduction in any medium or format, as long as you give appropriate credit to the original author(s) and the source, provide a link to the Creative Commons licence, and indicate if changes were made. The images or other third party material in this article are included in the article's Creative Commons licence, unless indicated otherwise in a credit line to the material. If material is not included in the article's Creative Commons licence and your intended use is not permitted by statutory regulation or exceeds the permitted use, you will need to obtain permission directly from the copyright holder. To view a copy of this licence, visit http://creativecommons.org/licenses/by/4.0/.

\section{References}

1. Morley C, Unwin M, Peterson GM et al (2018) Emergency department crowding: a systematic review of causes, consequences and solutions. PLoS ONE 13(8):e0203316. https://doi.org/10.1371/ journal.pone.0203316

2. Lin D, Patrick J, Labeau F (2014) Estimating the waiting time of multi-priority emergency patients with downstream blocking. Health Care Manag Sci 17:88-99. https://doi.org/10.1007/ s10729-013-9241-3

3. Kumle B, Gries A (2011) Zentrale Notaufnahme - Voraussetzungen, Organisationsformen, Prozesse. DIVI Jahrb 2011/2012 2015. German

4. Greiner F, Brammen D (2018) Routinedatenbasierte Versorgungsforschung in der klinischen Notfallmedizin - Herausforderungen und Möglichkeiten. Krankenhausreport 2018 Schwerpkt Bedarf und Bedarfsgerechtigkeit; 259-72. German

5. Kulla M, Baacke M, Schöpke T, et al (2014) Kerndatensatz „Notaufnahme“ der DIVI: Grundlage für Qualitätsmanagement und Versorgungsforschung in der Notaufnahme. NotfallRettungsmed;17(8):671-81. German. https://doi.org/10.1007/ s10049-014-1860- 9

6. Mazzali C, Duca P (2015) Use of administrative data in healthcare research. Intern Emerg Med 10:517-524. https://doi.org/10.1007/ s11739-015-1213-9

7. McHugh M, Neimeyer J, Powell E, Khare RK, Adams JG (2014) Is emergency department quality related to other hospital quality domains? Acad Emerg Med 21(5):551-557. https://doi.org/10. 1111/acem. 12376

8. Stelfox HT, Straus SE, Nathens A, Bobranska-Artiuch B (2011) Evidence for quality indicators to evaluate adult trauma care: a systematic review. Crit Care Med 39(4):846-859. https://doi.org/ 10.1097/CCM.0b013e31820a859a

9. Casalino E, Choquet C, Bernard J et al (2013) Predictive variables of an emergency department quality and performance indicator: a 1 -year prospective, observational, cohort study evaluating hospital and emergency census variables and emergency department time interval measurements. Emerg Med J 30(8):638-645. https://doi. org/10.1136/emermed-2012-201404

10. Schull MJ, Guttmann A, Leaver CA et al (2011) Prioritizing performance measurement for emergency department care: consensus 
on evidencebased quality of care indicators. Can J Emerg Med 13(5):300-309. https://doi.org/10.2310/8000.2011.110334 (E28-43)

11. Lamprecht J, Kolisch R, Pförringer D (2019) The impact of medical documentation assistants on process performance measures in a surgical emergency department. Eur J Med Res 24(1):1-8. https://doi.org/10.1186/s40001-019-0390-9

12. Nelson BL, Nicol DM (2020) DISCRETE-EVENT SYSTEM part I. Introduction to discrete-event system simulation, 5th edn. Pearson, London

13. Duguay C, Chetouane F (2007) Modeling and improving emergency department systems using discrete event simulation. SIMULATION 83(4):311-320. https://doi.org/10.1177/0037549707 083111

14. Trzeczak S (2013) Überfüllte notaufnahme. Ursachen, folgen und lösungen. NotfallRettungsmed 16(2):103-108. https://doi.org/10. 1007/s10049-012-1625-2 (German)

15. Epstein SK, Huckins DS, Liu SW et al (2012) Emergency department crowding and risk of preventable medical errors. Intern Emerg Med 7:173-180. https://doi.org/10.1007/ s11739-011-0702-8

16. Chen HC, Lee WC, Chen YL et al (2016) The impacts of prolonged emergency department length of stay on clinical outcomes of patients with ST-segment elevation myocardial infarction after reperfusion. Intern Emerg Med 11:107-114. https://doi.org/10. 1007/s11739-015-1330-5

17. Hörster AC, Kulla M, Brammen D, Lefering R (2018) Potenzial zur Erfassung von international etablierten Qualitätsindikatoren durch ein nationales Notaufnahmeregister: Eine systematische Literaturrecherche [Potential for the survey of quality indicators based on a national emergency department registry: a systematic literature search]. Med Klin Intensivmed Notfmed 113(5):409_ 417. https://doi.org/10.1007/s00063-016-0180-x

18. Brammen D, Greiner F, Kulla M et al (2020) Das AKTINNotaufnahmeregister - kontinuierlich aktuelle Daten aus der Akutmedizin : Ergebnisse des Registeraufbaus und erste Datenauswertungen aus 15 Notaufnahmen unter besonderer Berücksichtigung der Vorgaben des Gemeinsamen Bundesausschusses zur Ersteinschätzung [AKTIN-The German Emergency Department Data Registry-real-time data from emergency medicine : Implementation and first results from 15 emergency departments with focus on Federal Joint Committee's guidelines on acuity assessment]. Med Klin Intensivmed Notfmed, pp 1-10. German. https:// doi.org/10.1007/s00063-020-00764-2

19. Rygiel K, Fimmers R, Schacher S, Dormann H, Gräff I (2020) Ältere Notfallpatienten in der zentralen Notaufnahme : Eine Kennzahlenauswertung auf Basis des DIVI- Notaufnahmeprotokoll [Older emergency patients in the emergency department: a key performance indicator analysis based on the DIVI emergency department protocol]. Med Klin Intensivmed Notfmed 115(3):228-236. https://doi.org/10.1007/s00063-019-0595-2 (German)

20. Biber R, Bail HJ, Sieber C, Weis P, Christ M, Singler K (2012) Correlation between age, emergency department length of stay and hospital admission rate in emergency department patients aged $\geq 70$ years. Gerontology 59(1):17-22. https://doi.org/10. $1159 / 000342202$

21. Ardagh M (2010) How to achieve New Zealand's shorter stays in emergency departments health target. N Z Med J 123(1316):95-103

22. Freeman JV, Croft S, Cross S, Yap C, Mason S (2010) The impact of the $4 \mathrm{~h}$ target on patient care and outcomes in the emergency department: an analysis of hospital incidence data. Emerg Med J 27(12):921-927. https://doi.org/10.1136/emj.2009.085431

23. Forero R, Nahidi S, De Costa J et al (2019) Perceptions and experiences of emergency department staff during the implementation of the four-hour rule/national emergency access target policy in Australia: a qualitative social dynamic perspective. BMC Health Serv Res 19(1):1-14. https://doi.org/10.1186/s12913-019-3877-8

24. Schull M, Vermeulen M, Guttmann A, Stukel T (2015) Better performance on length-of-stay benchmarks associated with reduced risk following emergency department discharge: an observational cohort study. Can J Emerg Med 17(3):253-262. https://doi.org/10. 1017/cem.2014.39

25. Gemeinsamer Bundesausschuss (2018) Beschluss des Gemeinsamen Bundesausschusses über die Erstfassung der Regelungen zu einem gestuften System von Notfallstrukturen in Kran-kenhäusern gemäß § 136c Absatz 4 SGB V 2018. https://www.g-ba. de/downloads/39-261-3301/2018-04-19_Not-Kra-R_Erstfassung. pdf. Accessed 02 Sept 2020

26. Brammen D, Greiner F, Dormann H et al (2018) Lessons learned in applying the International Society for Pharmacoeconomics and Outcomes Research methodology to translating Canadian Emergency Department Information System Presenting Complaints List into German. Eur J Emerg Med 25(4):295-299. https://doi. org/10.1097/MEJ.0000000000000450

27. Kulla M, Brammen D, Greiner F et al (2016) Vom Protokoll zum Register - Entwicklungen für ein bundesweites Qualitätsmanagement in deutschen Notaufnahmen. Divi 2016 7(1):12-20. https:// doi.org/10.3238/DIVI.2016.0012-0020 (German)

28. Ahlbrandt J, Brammen D, Majeed RW et al (2014) Balancing the need for big data and patient data privacy - an IT infrastructure for a decentralized emergency care research database. Stud Health Technol Inform 205:750-754

29. Otto R, Schirrmeister W, Majeed RW et al (2019) Implementation of Emergency Department Performance Benchmarking Using R and LaTeX. Stud Health Technol Inform 267:238-246. https://doi. org/10.3233/SHTI190833

30. Greiner F, Erdmann B, Thiemann VS et al (2021) Der AKTINMonatsbericht: Plädoyer für ein standardisiertes Reporting in der Notaufnahme [Monthly in-house reports using the AKTIN Emergency Department Data Registry: advantages of standardised key figures. Development and implementation of a reporting system based on emergency department medical record data]. NotfallRettungsmed 1:1. https://doi.org/10.1007/s10049-021-00910-z (German)

31. Möckel M, Reiter S, Lindner T, Slagman A (2020) „Triagierung“ - Ersteinschätzung von Patienten in der zentralen Notaufnahme: Eine Übersicht mit systematischem Review ["Triage"-primary assessment of patients in the emergency department: an overview with a systematic review]. Med Klin Intensivmed Notfmed 115(8):668-681. https://doi.org/10.1007/s00063-019-0589-0 (German)

32. Slagman A, Behringer W, Greiner F, Klein M, Weismann D (2020) Medizinische Notfälle während der COVID-19-Pandemie-Analyse von Notaufnahmedaten in Deutschland [Medical emergencies during the COVID-19 pandemic - an analysis of emergency department data in Germany]. Dtsch Arztebl Int 117:545-552. https://doi.org/10.3238/arztebl.2020.00545 (German)

33. R Core Team (2020) R: a language and environment for statistical computing. R Foundation for Statistical Computing, Vienna, Austria. https://www.r-project.org/. Accessed 21 Oct 2020

34. Ellis PD (2010) The Essential Guide to Effect Sizes. Cambridge University Press

35. Cohen J (1988) The concepts of power analysis BT-statistical power analysis for the behavioral sciences (revised edition), 2nd edn. Erlbaum Associates, Hillsdale. http://www.utstat.toronto.edu/ brunner/oldclass/378f16/readings/CohenPower.pdf. Accessed 06 Nov 2020

36. Perdahl T, Axelsson S, Svensson P, Djärv T (2017) Patient and organizational characteristics predict a long length of stay in the emergency department-a Swedish cohort study. Eur J Emerg 
Med 24(4):284-289. https://doi.org/10.1097/MEJ.0000000000 000352

37. Frick J, Möckel M, Schmiedhofer M et al (2019) Fragebogen zur Inanspruchnahme der Notaufnahmen: Implikationen für die Patientenbefragung [Questionnaire for the utilization of the Emergency Department: implications for the patient survey]. Med Klin - Intensivmed Notfmed 114(1):38-44. https://doi.org/10.1007/ s00063-017-0345-2 (German)

38. Baier N, Geissler A, Bech M et al (2019) Emergency and urgent care systems in Australia, Denmark, England, France, Germany and the Netherlands-analyzing organization, payment and reforms. Health Policy (New York) 123:1-10. https://doi.org/10. 1016/j.healthpol.2018.11.001

39. Kulla M, Goertler M, Somasundaram R et al (2016) Bewertung von Qualitätsindikatoren für die Notaufnahme: Erstmalige
Anwendung eines modifizierten QUALIFY-Ansatzes mit nachfolgender interprofessioneller Expertendiskussion. NotfallRettungsmed 19(8):646-656. https://doi.org/10.1007/s10049-016-0236-8 (German)

40. Drynda S, Schindler W, Slagman A et al (2020) Evaluation of outcome relevance of quality indicators in the emergency department (ENQuIRE): study protocol for a prospective multicentre cohort study. BMJ Open 10(9):e038776. https://doi.org/10.1136/ bmjopen-2020-038776

Publisher's Note Springer Nature remains neutral with regard to jurisdictional claims in published maps and institutional affiliations. 